\title{
A EDUCAÇÃO EM BIOÉTICA NA DECLARAÇÃO UNIVERSAL SOBRE BIOÉTICA E DIREITOS HUMANOS
}

\author{
http://dx.doi.org/10.21527/2176-6622.2021.56.9888
}

Recebido em: 10/12/2019

Modificações solicitadas em: 26/1/2021

Aceito em: 2/2/2021

\section{Cristiani Pereira de Morais Gonzalez}

Autora correspondente. Universidade Federal da Paraíba - UFPB. João Pessoa/PB, Brasil. http://lattes.cnpq. br/4744410010610734. https://orcid.org/0000-0002-6075-2939. cristianipmorais@gmail.com

Maria Creusa de Araújo Borges

Universidade Federal da Paraíba - UFPB. João Pessoa/PB, Brasil.

\section{RESUMO}

No contexto de rápidos avanços tecnológicos e na ciência, a reflexão e a orientação sobre questões éticas alcançam centralidade e interessam à comunidade internacional. A necessidade dessa reflexão e/ou orientação coloca demandas e desafios para o campo da Bioética no quadro das normas internacionais e domésticas, com destaque para a Educação em Direitos Humanos. Nesse âmbito, é aprovada a Declaração Universal sobre Bioética e Direitos Humanos pela Unesco, em 2005, considerando a educação como uma questão-chave para a promoção da reflexão ética e para a orientação de escolhas e decisões dos governos, cidadãos e empresas, tendo como paradigma interpretativo a normativa internacional de proteção de direitos humanos. A partir de uma pesquisa descritiva, bibliográfica e documental, busca-se, então, examinar como a educação em Bioética está prevista nessa Declaração, explicitando o seu papel relativo à promoção universal dos princípios éticos em conformidade com os direitos humanos. Com vistas a alcançar esse objetivo, utilizando-se do método dedutivo de abordagem, são apresentadas desde as concepções de direitos humanos às reflexões sobre o direito à educação e à educação em Bioética. A análise indicou que, embora a educação constitua uma questão-chave para a Bioética, estando prevista no artigo 23 da citada Declaração como uma das medidas para a promoção desta, o processo de educar em Bioética não está detalhado, demandando posição doutrinária sobre a matéria. Ainda assim, o reconhecimento dessa educação é expressivo para a promoção do respeito à dignidade da pessoa no contexto das questões suscitadas pelo progresso científico e suas tecnologias.

Palavras-chave: Bioética; direitos humanos; declaração universal sobre bioética e direitos humanos; educação em bioética.

EDUCATION ON BIOETHICS IN THE UNIVERSAL DECLARATION ON BIOETHICS AND HUMAN RIGHTS

\section{ABSTRACT}

In the context of rapid technological advances and in science, reflection and guidance on ethical issues are central to and of interest to the international community. The need for such reflection and/or guidance poses demands and challenges to the field of Bioethics within the framework of international and domestic standards, with emphasis on Human Rights Education. In this context, the Universal Declaration on Bioethics and Human Rights was approved by UNESCO in 2005, constituting education as a key issue to promote ethical reflection and to guide the choices and decisions of governments, citizens and companies, having as interpretative paradigm the international standard for human rights protection. Based on a descriptive, bibliographic and documentary research, it then seeks to examine how education in Bioethics is provided for in this Declaration, explaining its role in the universal promotion of ethical principles in accordance with human rights. In order to achieve this objective, using the deductive method of approach, they are presented from conceptions of human rights to reflections on the right to education and education in Bioethics. The analysis indicated that, although education is a key issue for Bioethics, and is provided for in Article 23 of the aforementioned Declaration as one of the measures to promote it, the process of educating in Bioethics is not detailed, demanding a doctrinal position on the matter. Nevertheless, the recognition of this education is expressive for the promotion of respect for the dignity of the person in the context of issues raised by scientific progress and its technologies.

Keywords: Bioethics; human rights; universal declaration on bioethics and human rights; education in bioethics. 


\section{INTRODUÇÃO}

Na contemporaneidade, vislumbra-se a premente necessidade de formar a humanidade para (re)conhecer e lutar pelos direitos humanos, bem como para agir eticamente diante dos desafios diários.

Tal constatação decorre da percepção de que o ser humano está imerso em um contexto paradoxal, no qual, ao lado da exigência cada vez maior de reconhecimento dos direitos humanos, tem-se a não efetividade de muitos deles; e também complexo, em que se repensam algumas relações, tal qual entre os conhecimentos, e se passa a requerer uma educação que promova uma inteligência apta a se referir ao complexo (MORIN, 2000).

Fato é que, diferentemente de algum tempo atrás, hoje faz-se necessário formar generalistas, quer dizer, pessoas com conhecimentos abrangentes e diversificados, que dialoguem, até para se evitar a corrente fragmentação do que é complexo pelas especializações. Isso significa que todo e qualquer profissional, inclusive o da área jurídica, precisa estar apto para lidar com as complexas situações que surgem diariamente, e que, muitas vezes, dizem respeito à ética da vida (por exemplo, eutanásia e aborto), para cuja resolução não basta o conhecimento de uma área.

Vislumbra-se que a ética da vida é indispensável nas sociedades contemporâneas e que os assuntos de Bioética são importantes para todos, razão pela qual torna-se central o processo de educar os cidadãos nessa matéria. Com efeito, no contexto de rápidos avanços tecnológicos e na ciência, a reflexão e a orientação sobre questões éticas na contemporaneidade alcançam centralidade e os assuntos atinentes a elas interessam à comunidade internacional. Tem-se que a necessidade dessa reflexão e/ou orientação coloca demandas e desafios para o campo da Bioética no quadro das normativas internacionais e domésticas, com destaque para a Educação em Direitos Humanos. E é nesse âmbito, justamente, que é aprovada a Declaração Universal sobre Bioética e Direitos Humanos pela Unesco, em 2005, constituindo a educação uma questão-chave para a promoção da reflexão ética e, sobretudo, para a orientação de escolhas e decisões dos governos, cidadãos e empresas, tendo como paradigma interpretativo a normativa internacional de proteção de direitos humanos. Não obstante a educação se constituir como uma questão-chave para a Bioética, estando prevista explicitamente no artigo 23 da citada Declaração como uma das medidas para a sua promoção, o processo de educar em Bioética não está detalhado, demandando posição doutrinária sobre a matéria e exigindo respostas a serem trabalhadas na pesquisa sociojurídica.

Nesse âmbito, a questão norteadora da pesquisa consiste em: Como a educação em Bioética está prevista na Declaração Universal sobre Bioética e Direitos Humanos; quais os princípios e procedimentos a orientar os Estados na formulação de políticas legislativas e a orientar as ações dos cidadãos e as empresas com fundamento no diálogo interdisciplinar, pluralista e em conformidade com a normativa internacional de direitos humanos?

Com base nessa problemática, pretende-se examinar como a educação em Bioética está prevista na citada Declaração. Mais especificamente, almeja-se conceituar os direitos humanos e a Bioética; relacionar a Bioética com os direitos humanos; pensar o direito à educação e a educação em Bioética e analisar e descrever a educação em Bioética estabelecida na Declaração Universal sobre Bioética e Direitos Humanos.

Visando a alcançar esses fins, procede-se a uma pesquisa descritiva, viabilizada a partir do método de abordagem dedutivo e da técnica de pesquisa da documentação indireta em suas duas modalidades - pesquisa bibliográfica e pesquisa documental.

Por fim, convém explicitar que o presente artigo está organizado em quatro tópicos, com o primeiro sendo destinado à exposição de concepções de direitos humanos; o segundo, de noções de Bioética; o terceiro, de relações entre Bioética e direitos humanos e o quarto e último, de reflexões sobre o direito à educação e a educação em Bioética, dando-se ênfase à descrição desta a partir da Declaração Universal sobre Bioética e Direitos Humanos.

\section{DIREITOS HUMANOS: O QUE SÃO?}

Antes de tudo, para que se possa compreender o que são direitos humanos, cabe fazer uma sucinta exposição acerca de sua afirmação histórica. O processo de afirmação histórica dos direitos humanos, habitual- 
mente é dividido em "gerações", ${ }^{1}$ com fundamento no percurso histórico que inspirou sua criação (MAZZUOLI, 2017). Na verdade, normalmente, em três gerações de direitos humanos, com relação às quais há certo consenso, todavia, há teóricos que adicionam uma quarta e até mesmo uma quinta e sexta gerações. A partir de Mazzuoli (2017), no entanto, tratar-se-á de quatro.

A primeira geração corresponde aos direitos de liberdade, ou seja, aos direitos civis e políticos, a exemplo do direito à liberdade, e é fruto das revoluções liberais ocorridas no século 18. De acordo com Mazzuoli (2017), cuida-se de direitos que, tendo por titular o indivíduo, são oponíveis ao Estado. Esclarecendo melhor, está-se a falar de direitos que exigem "um não fazer" por parte do Estado.

A segunda geração equivale aos direitos de igualdade, isto é, aos direitos econômicos, sociais e culturais, como o direito à educação, e nasceu no início do século 20, como resultado da transição do Estado Liberal para o Estado Social. Não obstante esses direitos se reportem também à pessoa individual (SARLET, 2015), a nota distintiva deles é sua dimensão positiva, uma vez que se pretende, com seu reconhecimento, a garantia da participação do indivíduo no bem-estar social (GONÇALVES, 2013). Trata-se, em suma, de direitos que requerem "um fazer" por parte do Estado.

A terceira geração, por sua vez, diz respeito aos direitos de fraternidade, tal como o direito ao desenvolvimento, e emana do contexto posterior à Segunda Guerra Mundial. Para Sarlet (2015), a distinção desses direitos reside na sua titularidade coletiva, muitas vezes indefinida e indeterminável.

No que concerne à quarta geração, vale sublinhar que, para Bonavides (2011), ela resulta da globalização dos direitos fundamentais e abarca os direitos à democracia, à informação e ao pluralismo. Já para Bobbio (2004), tais direitos são relativos aos efeitos da pesquisa biológica, que admitirá manipulação do patrimônio genético das pessoas. Há, ainda, estudiosos como Baruffi (2006), que incluem a Bioética como direito de quarta geração.

Seja qual for o número de gerações apontadas para organizar os direitos humanos de acordo com determinado grupo de direitos surgidos em uma época histórica específica, importa perceber que tais direitos constituem tema global da atualidade (ALVES, 2015).

Ultrapassadas essas considerações preliminares, pode-se retomar a questão central deste tópico: O que são direitos humanos?

A análise da problemática dos direitos humanos requer considerações preliminares sobre a matéria (BORGES, 2009). Uma primeira questão consiste na discussão relativa à existência de um aparente pleonasmo nas expressões "direitos humanos", "direitos do homem" (COMPARATO, 2005; BOBBIO, 2004). A utilização das expressões, aparentemente repetitiva, justifica-se pelo fato de os direitos humanos se constituírem como "[...] algo que é inerente à própria condição humana, sem ligação com particularidades determinadas de indivíduos ou grupos" (COMPARATO, 2005, p. 57).

Na condição de direitos que têm como referência o princípio fundamental da dignidade da pessoa humana, o seu conteúdo - este, sim, dotado de historicidade - é determinado pelas necessidades sociais de cada época, com vistas ao favorecimento do princípio maior da dignidade. Dessa forma, justifica-se a pertinência da expressão "direitos humanos", pois é necessário enfatizar que esses direitos têm como referência primordial a dignidade da pessoa humana, procurando promovê-la.

Os direitos humanos referem-se a direitos cujo conteúdo é variável, não podendo ser estabelecidos in totum (BOBBIO, 2004). Assim, o seu processo de reconhecimento sociojurídico caracteriza-se por uma constante abertura. Por isso, afirma-se que o rol dos direitos humanos traz a característica da inexauribilidade, expressando uma dogmática aberta (RAMOS, 2002). Na verdade, nesta seara, protege-se um direito pelo seu conteúdo, orientado pelo princípio da dignidade da pessoa humana, com referência às necessidades estabelecidas historicamente.

É válido esclarecer que "A proposta de triangulação dos direitos humanos em 'gerações' é atribuída a Karel Vasak [...]" (MAZZUOLI, 2017, p. 51) e que há quem critique esse pensamento sob o argumento de que as gerações de direitos conduzem a uma ideia de sucessão e consequente substituição, o que não seria apropriado. Nesse sentido, Sarlet (2015) defende o uso da nomenclatura "dimensões". Não obstante isso, considerando os ensinamentos de Mazzuoli (2017) e, sobretudo, seu uso habitual, emprega-se o termo "geração" neste trabalho. 
Assim sendo, o rol dos direitos humanos traz a marca da mutabilidade. Direitos não mencionados em instrumentos internacionais de direitos humanos passam a ser reconhecidos em recentes tratados, como é o caso dos direitos ao desenvolvimento, à qualidade de vida, das pessoas com necessidades especiais, ao patrimônio genético, à proteção de dados, de não proliferação de armas nucleares, entre outros. Como afirma Bobbio (2004), a consideração de um direito como fundamental depende das circunstâncias históricas e culturais, pois essas circunstâncias detêm a característica da mutabilidade. Não há, portanto, a possibilidade de atribuição de um fundamento absoluto a direitos atrelados a condições históricas.

Podem, também, ser destacadas concepções de direitos humanos: uma tida como tradicional (em que se apresentam os elementos centrais que estabelecem a base da doutrina dominante), e outra como crítica (que se contrapõe justamente ao conceito tradicional).

Conforme Peterke (2013), o conceito tradicional dos direitos humanos pode ser sintetizado na afirmação de que eles são direitos pré-estatais que pertencem a todo o ser humano como pessoa. A alegação de que são direitos "pré-estatais" significa que essas garantias existem independentemente do seu reconhecimento pelo Estado. O elemento "todo ser humano" sinaliza que o único pressuposto é pertencer ao gênero humano. E a afirmação de que os direitos humanos pertencem a todo o ser humano "como pessoa" refere-se à pessoa como conceito normativo baseado na ideia de dignidade humana.

Como representante de uma teoria crítica dos direitos humanos, Flores (2009) critica a teoria tradicional afirmando que ela começa falando dos direitos e termina falando dos direitos, quer dizer, sustenta uma concepção a priori dos direitos humanos, que faz com que se pense ter direitos antes de ter as capacidades e as condições adequadas para poder exercê-los. Propondo uma perspectiva nova, integradora, crítica e contextualizadora em práticas sociais emancipadoras, o mencionado autor defende movimento diverso da teoria tradicional, sublinhando que os direitos vêm depois das lutas pelo acesso aos bens.

Para esse autor, os direitos humanos constituem um tema de alta complexidade, ${ }^{2}$ que deve ser pensado por meio de três níveis: "o quê?", "por quê?" e "para quê?"

Como conceituar os direitos humanos constitui um dos objetivos deste estudo, focaliza-se o primeiro nível. Sendo assim, a partir de Flores (2009), pode-se afirmar que os direitos humanos são resultado de lutas que os seres humanos colocam em prática para ter acesso aos bens necessários à vida, ou seja, para viver com dignidade, esta sendo entendida como um fim material.

Na Declaração Universal sobre Bioética e Direitos Humanos, mais especificamente em seu artigo 3o, há, inclusive, um princípio relacionando dignidade humana e direitos humanos, cujo conteúdo reside não apenas no respeito pleno da dignidade humana e dos direitos humanos e das liberdades fundamentais, como também na decisão de dar prioridade aos interesses e ao bem-estar da pessoa em detrimento do interesse exclusivo da ciência ou da sociedade.

\section{A QUE SE REFERE A BIOÉTICA?}

A Bioética, como campo do saber, surge na década de 70 do século 20, nos Estados Unidos da América do Norte. Efetivamente, esse termo se popularizou a partir de janeiro de 1971, quando Van Rensselaer Potter

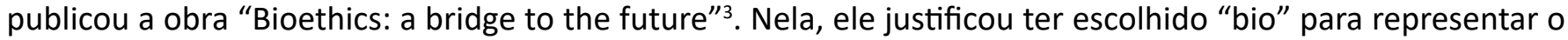
conhecimento biológico dos sistemas viventes, e "ética" para retratar o conhecimento dos sistemas de valores humanos (OLIVEIRA, 1997). A contribuição desse estudioso para o surgimento dessa disciplina/área de pesquisa foi tamanha que ele é considerado seu criador, como mencionam Garrafa e Costa (2000).

Importa consignar que o campo da Bioética passa por transformações diante da condição de historicidade do fazer humano e dos rápidos avanços científicos e tecnológicos. De fato, conforme explica Neves (2014), quando de seu surgimento, a Bioética, na qualidade de ética aplicada, manifestava-se como afirmação de uma

\footnotetext{
Flores (2009) discorre sobre as complexidades cultural, empírica, jurídica, científica, filosófica, política e econômica.

3 Vale esclarecer que, a despeito de esse vocábulo ter se popularizado com Van Rensselaer Potter, fato que se enfatiza aqui, para Freire (2018) ele teria apenas definido e revivido, de forma aparentemente independente, a palavra bioética, posto que esta teria sido cunhada primeiramente por Fritz Jahr em 1927 e referida ainda por Albert Schweitzer em 1936.
} 
nova expressão do dever; mas, hoje, se assume cada vez mais como ética cívica nas sociedades democráticas, enfrentando o desafio de não só se manter fiel ao sentido do dever como exprimir os interesses da maioria dos cidadãos afetados pelos progressos biotecnológicos.

$O$ advento da Bioética foi desencadeado pelo progresso das biotecnologias e sua aplicação ao ser humano, o que veio a criar realidades em relação às quais as pessoas não sabiam como deveriam agir (NEVES, 2014). Constata-se que ela surgiu como expressão da necessária subordinação da ciência ao humano, com vistas a resguardar a dignidade da pessoa, em especial daquela que estava em situação de vulnerabilidade, por exemplo, em decorrência de pandemias.

Nas suas décadas de história, a Bioética foi se desenvolvendo de uma forma avassaladora, não apenas intensificando o que constituiu parte essencial do seu sucesso desde sua origem, notadamente a autonomia no plano pessoal e a institucionalização no plano social (NEVES, 2014), como se revestindo de poder, o que a afastou da sua lógica de dever.

Ao longo do tempo, a Bioética foi mudando seu enfoque do indivíduo e da sua autonomia para incidir na comunidade e na justiça social, e se fixar em diversas comunidades em distintos países e ainda na solidariedade internacional (NEVES, 2014).

Percebe-se que houve um alargamento do domínio da Bioética, de tal modo que ela deixou de se situar, exclusivamente, no plano biomédico para abarcar outras esferas, como a ambiental e a social. Além disso, não obstante haja críticas a esta postura, ${ }^{4}$ deve-se ponderar que há princípios orientadores do que se considera uma conduta ética em relação à vida (OLIVEIRA, 1997).

Versando sobre a bioética laica, Oliveira (1997) declara que são adotados como princípios a autonomia ou o respeito à pessoa (o que acarreta que o ser humano tem direito de responder por seus atos, de exercer o direito de escolha, devendo os profissionais respeitarem sua vontade); a beneficência ou não-maleficência (que suscita a ideia de que toda ação na área de saúde deve objetivar o bem da pessoa, evitando-se danos) e a justiça (que corresponde à justa distribuição dos bens e serviços). ${ }^{5}$ Ao tratar dos princípios fundamentais da bioética, Bellino (1997) também os menciona. De igual modo procede Anjos (2000), apontando-os, embora para explicitar percepções num contexto específico - o latino-americano.

Além do mais, é preciso destacar que há uma pluralidade de perspectivas teóricas atinentes à Bioética, inclusive em âmbito internacional, bem como uma variedade de concepções acerca da mesma, sendo válido evidenciar algumas destas.

Etimologicamente, tal como esclarece Oliveira (1997), bioética significa ética da vida, posto que a palavra é constituída pelos vocábulos de origem grega "bios" (vida) e "ética" (costumes, valores relativos a determinado agrupamento social em algum momento de sua história).

Ainda segundo essa autora, a Bioética tem como objetivo geral buscar benefícios e garantir a integridade do ser humano, tendo como fio condutor o princípio da defesa da dignidade humana; e possui uma dupla faceta (é um movimento e uma disciplina) a qual lhe confere a peculiaridade de ser, ao mesmo tempo, reflexão e ação.

A Bioética, também, teria como objetivo contribuir para que as pessoas estabeleçam uma conexão entre a cultura científica e a cultura humanística, de maneira que seja possível discutir e avaliar os impactos que a tecnologia possa vir a causar sobre a vida (DORA; TEIXEIRA PRIMO; ARAÚJO, 2019).

Sendo assim, a Bioética apresenta-se hoje como uma das disciplinas de maior relevo no controle da biotecnologia e no enfrentamento dos dilemas morais que advêm das fricções entre o desenvolvimento técnico-científico e a proteção da vida humana (MOURA; MEDEIROS, 2015).

Com fundamento em Bellino (1997), pode-se observar que ela é mais que uma disciplina, é um território, um terreno de confronto de saberes acerca de problemas surgidos em decorrência do progresso das ciências biomédicas, das ciências da vida e mesmo das ciências humanas, dentro do qual a complexidade cultural e

\footnotetext{
Como afirma Campbell (2000), dentro da bioética há uma reação contra o domínio da abordagem pautada em princípios.

5 Embora Oliveira (1997) faça referência a outros princípios, como os princípios da qualidade de vida e da alteridade, e constate que não se chegará a um entendimento no que concerne aos princípios da bioética, seja quantitativa ou qualitativamente, ela sustenta que esses três princípios constituem a chamada "trindade da bioética".
} 
científica confere ao estatuto epistemológico da bioética uma conotação multidisciplinar. Faz-se necessário, então, adotar uma visão de Bioética interdisciplinar, flexível e aberta, nunca dogmática e sempre em revisão (CASADO, 2009a). Por fim, convém citar alguns temas da Bioética, são eles: os direitos reprodutivos, o acesso aos meios de manutenção da saúde e da vida e as manipulações genéticas.

\section{INTERSEÇÕES ENTRE BIOÉTICA E DIREITOS HUMANOS}

Primeiramente faz-se imprescindível sublinhar que a Bioética está incumbida de pensar um mínimo moral retomando justamente a discussão acerca dos direitos individuais e sociais, isto é, dos direitos humanos na ordem democrática. Trata-se, com efeito, de disciplina preocupada com a humanização, que é condição necessária para que os direitos humanos e a cidadania possam, efetivamente, acontecer nas esferas privada e pública (ZANCANARO, 2007).

Assim, observa-se que a Bioética tem como parâmetro a proteção dos direitos humanos em suas reflexões desde o início da vida e ao fim dela, no que respeita, por exemplo, às questões de reprodução assistida, de pesquisa com seres humanos e de eutanásia, e contribui para que tais direitos sejam concretizados.

Por outro lado, ao assumir como paradigma interpretativo e de ação a perspectiva de proteção dos direitos humanos, as ações voltadas à Bioética são humanizadas, razão pela qual necessitam levar em consideração alguns princípios, como dignidade humana, qualidade de vida, felicidade e justiça.

Humanizar as relações em sociedade, cada vez mais mediadas pelas tecnologias e pelo avanço científico veloz, seria, portanto, um ponto de interseção entre a Bioética e os direitos humanos, com base no compartilhamento de estruturas principiológicas com aporte no respeito à dignidade humana (ZANCANARO, 2007).

Relacionando essas matérias, Oliveira (1997) realça a importância do movimento bioético na luta pelos direitos humanos, afirmando que esta encontrará naquele um paradigma de reflexão e ação, com disposição para orientar o desenvolvimento científico rumo à priorização da função social das biociências e à promoção da cidadania.

Nesse cenário, também, merece ser mencionado o Biodireito, o qual, como interface entre Bioética e Direito, ou fronteira da biotecnologia e dos direitos humanos, consiste na compreensão do fenômeno jurídico enquanto conhecimento prático empenhado na promoção da vida humana (SILVA, 2003).

Tal concepção implica reconhecer que o Biodireito, para além das prerrogativas humanitárias já asseguradas, deve incorporar, em seu campo de reivindicação, prerrogativas negadas, quer dizer, envolver-se com os direitos humanos relacionados ao subdesenvolvimento - por exemplo, o direito à alimentação e o direito à renda - e ao sobredesenvolvimento - à semelhança do direito ao sigilo de dados genéticos e do direito de não se sujeitar à obstinação terapêutica.

\section{DO DIREITO À EDUCAÇÃO E DA EDUCAÇÃO EM BIOÉTICA NA DECLARAÇÃO DA UNESCO}

De início, vale esclarecer que, como um direito social, o direito à educação está enquadrado na segunda geração de direitos humanos. Integra, assim, o elemento social da cidadania (BORGES, 2008). Ademais, ele constitui direito subjetivo que deve ser tutelado pelo Estado, o que significa que a pessoa pode requerê-lo em juízo. Torna-se relevante enfatizar que esse direito é reconhecido tanto em instrumentos internacionais quanto nacionais.

Enfocando o plano internacional, de imediato faz-se necessário destacar a Declaração Universal dos Direitos Humanos, proclamada em 10 de dezembro de 1948, em cujo documento o direito à educação é reconhecido no artigo 26 , como direito universal:

Toda pessoa tem direito à educação. A educação deve ser gratuita, ao menos no que diz respeito à instrução elementar e fundamental. A instrução elementar será obrigatória. A instrução técnico-profissional haverá de ser generalizada; o acesso aos estudos superiores será igual para todos em função dos respectivos méritos $[\ldots]^{6}$ (ONU, 1948, p. 8, tradução nossa).

\footnotetext{
6 No texto original: "1. Toda persona tiene derecho a la educación. La educación debe ser gratuita, al menos en lo concerniente a la instrucción elemental y fundamental. La instrucción elemental será obligatoria. La instrucción técnica y profesional habrá de ser generalizada; el acceso a los estudios superiores será igual para todos, en función de los méritos respectivos [...]" (ONU, 1948, p. 8).
} 


\section{Direito Debate}

A EDUCAÇÃO EM BIOÉTICA NA DECLARAÇÃO UNIVERSAL SOBRE BIOÉTICA E DIREITOS HUMANOS Cristiani Pereira de Morais Gonzalez - Maria Creusa de Araújo Borges

No Pacto Internacional dos Direitos Econômicos, Sociais e Culturais, adotado em 1966 e vigente a partir de 3 de janeiro de 1976, tal direito é tratado no artigo 13, sendo reiterado como direito universal nos seguintes termos: "1. Os Estados partes no presente Pacto reconhecem o direito de toda pessoa à educação. [...]"7 (ONU, 1966, p. 5, tradução nossa).

Na Declaração e Programa de Ação de Viena, adotada em 25 de junho de 1993, o direito à educação está positivado basicamente (uma vez que previsto em outros dispositivos também) no artigo 33 da Parte I, no qual se dispõe que "A Conferência Mundial de Direitos Humanos reitera o dever dos Estados [...] de orientar a educação de maneira que se fortaleça o respeito dos direitos humanos e das liberdades fundamentais [...]" 8 (ONU, 1993, p. 29, tradução nossa).

Nessa Declaração enfatiza-se mesmo, de forma expressa, uma educação em direitos humanos, isto é, uma prática social orientada para a socialização numa cultura de respeito, defesa e promoção dos direitos humanos (BORGES, 2008), tanto que se reserva uma seção para cuidar da educação em matéria de direitos humanos - item " $D$ " da Parte II (parágrafos 78 a 82).

$\mathrm{Na}$ Constituição da República Federativa do Brasil de 1988 (CF/88), mais especificamente em seu artigo 6 6, o direito à educação consta como direito social, sendo válido sublinhar que ele tem primazia em relação aos outros direitos sociais (BORGES, 2008).

Esse direito é especificado na seção I (Da educação) do capítulo III (Da Educação, da cultura e do desporto) do título VIII (Da ordem social), ou, em outros termos, nos artigos 205 a 214 da CF/88. Consoante o artigo 205, a educação é direito de todos e dever do Estado e da família, devendo ser promovida com a colaboração da sociedade. No artigo 208, especifica-se a efetivação do direito à educação, por parte do Estado, por meio de algumas garantias, como educação básica obrigatória e gratuita dos 4 (quatro) aos 17 (dezessete) anos de idade.

Ante o exposto, não restam dúvidas acerca do reconhecimento do direito à educação nos planos externo e interno. Em que consiste (deve consistir), porém, a educação no contexto atual? E a que faz alusão uma educação em bioética?

A educação é um operador de aprendizagem da cultura, e, como instituição e prática social, ela precisa vir a ser base para a projeção do porvir (ALMEIDA, 2014).

Assim, observando o contexto vivenciado (que é complexo), faz-se imprescindível pensar e desenvolver uma educação complexa, que pode ser facilitada a partir da consideração de alguns princípios intimamente relacionados com as preocupações da bioética, tais como o de que, para viabilizar a sustentabilidade da vida no planeta, deve-se avaliar os prognósticos da tecnociência para o amanhã que se inicia hoje, problematizando a ideia do progresso ilimitado da ciência; e o de responder com atitudes condizentes com os valores éticos da vida e da diversidade cultural diante da sociedade do terror (ALMEIDA, 2014).

Nessa conjuntura, sabendo-se que a educação pode tanto humanizar quanto desumanizar (ZANCANARO, 2007), e que é preciso estabelecer uma consciência bioética, considerando-se "um crime contra a humanidade" a atitude de negar à sociedade a oportunidade de acesso ao saber e às reflexões da micro e da macrobioética (OLIVEIRA, 1997); assim entendido, torna-se necessário criar e instituir programas de educação em bioética, tanto formais quanto informais, logo, de responsabilidade das instituições formais de ensino, e a cargo de atores do movimento bioético.

Discorrendo sobre o desenvolvimento de programas de educação em bioética, Have (2014) observa que o número de programas de ensino de ética cresceu rapidamente nos primeiros anos da década de 70, primeiramente nas faculdades de Medicina nos Estados Unidos da América, mas, desde então, o escopo da educação em bioética teria se ampliado consideravelmente, de modo que o ensino de ética passou a ser oferecido não só durante a Graduação como depois dela - em Especializações, programas de Mestrado e de Doutorado, sem olvidar ambientes clínicos.

\footnotetext{
No texto original: "1. Los Estados Partes en el presente Pacto reconocen el derecho de toda persona a la educación [...]" (ONU, 1966, p. 5).

8 No texto original: "La Conferencia Mundial de Derechos Humanos reitera el deber de los Estados [...] de encauzar la educación de manera que se fortalezca el respeto de los derechos humanos y las libertades fundamentales [...]" (ONU, 1993, p. 29).
} 
Apesar dos avanços, deve-se mencionar que a educação em bioética, particularmente em âmbito global, enfrenta vários desafios.

Com efeito, tal como observa Have (2014), não está claro se ela se deteriora sob pressões econômicas e políticas em Universidades, substituindo-se pessoal experiente por adjuntos temporários e cursos on-line, assim como se o ensino da ética tem sido usado por formuladores de políticas como um tipo de remédio paliativo. É necessário citar, também, consoante o mesmo autor, a enorme heterogeneidade do campo, da qual decorre a percepção de que não se sabe ao certo o que tal educação deve implicar dentro de um mesmo país, ainda mais porque diferentes tipos de programas são oferecidos, abordagens e métodos didáticos diferem, 0 número de horas de ensino é amplo e o curso de Ética não está programado nas mesmas fases do currículo.

Não obstante essas dificuldades, é fundamental que a bioética seja ministrada nos cursos universitários, não devendo seu ensino estar restrito aos ciclos básicos. Para tanto, a bioética deve ser trabalhada entre, através e para além das disciplinas, de maneira inter-multitransdisciplinar. Ademais, devem ser oferecidos módulos de formação continuada ao longo dos cursos (REGO; ROSITO; YAMADA, 2007).

Defende-se também que a educação em Bioética precisa desenvolver uma perspectiva global baseada em noções éticas, tais como solidariedade, dignidade humana e responsabilidade social (HAVE, 2014).

A partir dessas considerações, pode-se proceder à análise e descrição da educação em Bioética na Declaração Universal sobre Bioética e Direitos Humanos, aprovada pela 33ạ sessão da Conferência Geral da Unesco, em 19 de outubro de 2005.

Antes disso, importa destacar que essa Declaração foi fruto de mobilizações sociais intensas (SILVA; MEDEIROS, 2015) e possui forte teor social (OLIVEIRA; VILLAPOUCA; BARROSO, 2006). Ao revelar sobre o que trata, a Declaração Universal sobre Bioética e Direitos Humanos apresenta, em seu artigo 1으, uma concepção mais ampla de Bioética, levando em consideração as dimensões social, jurídica e ambiental imbricadas nas questões éticas suscitadas pela Medicina, pelas ciências da vida e pelas tecnologias que lhes estão associadas, na sua aplicação aos seres humanos.

No que diz respeito à educação em Bioética, a supracitada Declaração reserva um artigo para debatê-la juntamente com a formação e a informação em Bioética, ${ }^{9}$ ou seja, o artigo 23, o qual está inserido dentre as medidas para a promoção da Declaração sob o título de "Educação, formação e informação em matéria de Bioética".

Logo no primeiro parágrafo do artigo 23 são revelados os objetivos dessa educação: promover os princípios enunciados na presente Declaração e assegurar uma melhor compreensão das implicações éticas dos progressos científicos e tecnológicos, em particular entre os jovens. Ademais, frisa-se a responsabilidade dos Estados na sua consecução, quando se estabelece que eles devem "[...] esforçar-se não só por fomentar a educação e formação relativas à bioética em todos os planos, como também por estimular os programas de informação e difusão de conhecimentos sobre bioética" ${ }^{10}$ (UNESCO, 2005, p. 10, tradução nossa).

Note-se a defesa da educação em Bioética em "todos" os níveis, e não apenas nas escolas de segundo grau (Ensino Médio) como sustenta Oliveira (1997) ao referir que este é o público-alvo prioritário para o trabaIho de despertar uma consciência ética. Vislumbra-se, ainda, uma abertura para a efetivação dessa educação fora do ensino formal, direcionada a toda a sociedade, posto que devem ser estimulados programas de informação e difusão relativos à Bioética.

No parágrafo 20 do artigo em questão, ao mesmo tempo em que se reforça o papel dos Estados na efetivação da educação em Bioética, admitindo-se que os mesmos convidem outras entidades a cooperar nessa tarefa, ampliam-se os interlocutores envolvidos ao se estabelecer que "os Estados devem incentivar as or-

\footnotetext{
Como está saliente no artigo 23 da citada Declaração e esclarece Casado (2009b), educação-formação distingue-se de informação na medida em que mediante esta transmitem-se dados e conhecimentos, porém sem avaliação/orientação e aqueles termos implicam um passo a mais, envolve avaliação e tomadas de decisão (desenvolvimento da consciência).

${ }^{10}$ No texto original: "[...] esforzarse no sólo por fomentar la educación y formación relativas a la bioética en todos los planos, sino también por estimular los programas de información y difusión de conocimientos sobre la bioética" (UNESCO, 2005, p. 10).
} 
ganizações intergovernamentais internacionais e regionais, assim como as organizações não governamentais internacionais, regionais e nacionais para participar desta tarefa"11 (UNESCO, 2005, p. 11, tradução nossa).

Não obstante a educação se constituir como uma questão-chave para a Bioética, estando prevista explicitamente no artigo 23 da citada Declaração como uma das medidas para a sua promoção, o processo de educar em Bioética não está detalhado, demandando posição doutrinária sobre a matéria. Ainda assim, o reconhecimento da educação representa um expressivo destaque para a promoção do respeito à dignidade da pessoa humana no contexto das questões suscitadas pelo progresso científico e suas tecnologias.

Cabe realçar ainda que, apesar de a Declaração Universal sobre Bioética e Direitos Humanos não conter maiores detalhes acerca da educação em Bioética que deve ser desenvolvida, ${ }^{12}$ por exemplo, quais conteúdos e metodologias podem concretizá-la, tal Declaração tem muita importância no contexto atual, pois enuncia princípios que interligam ética e direitos humanos e prevê a necessidade de se promover a educação em Bioética, delineando as obrigações dos Estados-partes.

Nesse quadro, com o reforço da previsão da educação em Bioética nesse instrumento internacional, apreende-se um direito cada vez mais necessário e indispensável, a saber: o direito à educação em Bioética, um direito que emerge diante das necessidades históricas condicionadas pela mediação das relações sociais pelos avanços tecnológicos e científicos.

Para efetivá-lo, é preciso fomentar a educação (e a formação) atinente à Bioética com base nos princípios da própria Declaração Universal sobre Bioética e Direitos Humanos e a partir de uma atitude que promova o respeito às diferentes cosmovisões e a abertura aos avanços do conhecimento (CASADO, 2009b), com fundamento no pluralismo, na tolerância, na democracia e no respeito aos direitos humanos.

\section{CONSIDERAÇÕES FINAIS}

Neste artigo buscou-se verificar como a educação em Bioética está prevista na Declaração Universal sobre Bioética e Direitos Humanos da Unesco. No contexto de rápidos avanços tecnológicos e na ciência, a reflexão e a orientação sobre questões éticas na contemporaneidade alcançam centralidade e os assuntos atinentes a elas interessam à comunidade internacional. A necessidade dessa reflexão e/ou orientação coloca demandas e desafios para o campo da Bioética no quadro das normativas internacionais e domésticas, com destaque para a Educação em Direitos Humanos. Nesse âmbito, na Declaração Universal sobre Bioética e Direitos Humanos da Unesco a educação constitui-se como uma questão-chave para a promoção da reflexão ética e, sobretudo, para a orientação de escolhas e decisões dos governos, cidadãos e empresas, tendo como paradigma interpretativo a normativa internacional de proteção de direitos humanos. Não obstante a educação se constituir como uma questão-chave para a Bioética, estando prevista explicitamente no artigo 23 da citada Declaração como uma das medidas para a sua promoção, o processo de educar em Bioética não está detalhado, demandando posição doutrinária sobre a matéria, exigindo respostas a serem trabalhadas na pesquisa sociojurídica.

Nesse âmbito, a questão norteadora da pesquisa consistiu em: Como a educação em Bioética está prevista na Declaração Universal sobre Bioética e Direitos Humanos, quais os princípios e procedimentos a orientar os Estados na formulação de políticas e a orientar as ações dos cidadãos e das empresas com fundamento no diálogo interdisciplinar, pluralista e em conformidade com a normativa internacional de direitos humanos?

Nesse quadro, a educação em Bioética está prevista no artigo 23 da Declaração da Unesco e consta entre as medidas para a sua promoção. No parágrafo 10 são expostos os objetivos dessa educação, assim como é frisada a responsabilidade dos Estados para sua efetivação. Já no parágrafo 2으, ao mesmo tempo em que se reforça o papel dos Estados na sua consolidação, ampliam-se os interlocutores envolvidos, admitindo-se a atuação de organizações intergovernamentais e não governamentais. Além do mais, foi observado que ques-

\footnotetext{
$\overline{11}$ No texto original: "[2.] Los Estados deberían alentar a las organizaciones intergubernamentales internacionales y regionales, así como a las organizaciones no gubernamentales internacionales, regionales y nacionales, a que participen en esta tarea" (UNESCO, 2005, p. 11).

12 Há estudiosos que se debruçam sobre a descrição dessa educação, assim como faz Freire (2018) ao propor, em seu artigo, temas atuais de bioética (e também de biossegurança) conduzidos a docentes que trabalham com adolescentes de 12 a 17 anos, e mesmo com alunos mais maduros, inclusive na Universidade.
} 


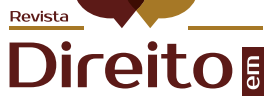 \\ Debate}

A EDUCAÇÃO EM BIOÉTICA NA DECLARAÇÃO UNIVERSAL SOBRE BIOÉTICA E DIREITOS HUMANOS

Cristiani Pereira de Morais Gonzalez - Maria Creusa de Araújo Borges

tões pedagógicas, como temas a constar no currículo e metodologia a ser adotada, não foram mencionadas nessa Declaração, razão pela qual pode-se concluir que o processo de educar em Bioética não está detalhado no documento sub examine.

Ainda assim, cabe afirmar que, sendo a educação em Bioética um instrumento relevantíssimo a ser utilizado em prol do desenvolvimento de uma consciência bioética para promoção do respeito à dignidade da pessoa humana diante das questões éticas suscitadas pelo progresso e suas tecnologias aplicadas, o fato de ela estar prevista na Declaração Universal sobre Bioética e Direitos Humanos representa um expressivo avanço no processo de afirmação histórica do direito à educação nessa matéria. Importa, sobretudo, destacar que a previsão expressa, em instrumento internacional de proteção de direitos humanos, da educação em Bioética nos incita a pensar sobre esse direito, sua estrutura principiológica, suas fontes e aspectos relativos ao seu conteúdo essencial.

\section{REFERÊNCIAS}

ALMEIDA, Maria da Conceição de. Educação, complexidade e ética da diversidade. In: PORTO, Dora et al. (org.). Bioética: saúde, pesquisa, educação. Brasília: CFM; SBB, 2014. p. 203-221. Vol. 2.

ALVES, José Augusto Lindgren. Os direitos humanos como tema global. São Paulo: Perspectiva, 2015.

ANJOS, Márcio Fabri dos. Bioética nas desigualdades sociais. In: GARRAFA, Volnei; COSTA, Sérgio Ibiapina F. (org.). A bioética no século XXI. Brasília: Editora Universidade de Brasília, 2000. p. 49-65.

BARUFFI, Helder. Direitos humanos e educação: uma aproximação necessária. Revista Jurídica Unigran, Dourados, n. 15, p. 39-54, jan./jun. 2006. Disponível em: http://www.dhnet.org.br/educar/textos/baruffi_dh_educ_aproximacao_necessaria.pdf. Acesso em: 3 dez. 2018.

BELLINO, Francesco. Fundamentos da bioética: aspectos antropológicos, ontológicos e morais. Tradução Nelson Souza Canabarro. Bauru: Edusc, 1997.

BOBBIO, Norberto. A era dos direitos. 3. reimp. Tradução Carlos Nelson Coutinho. Rio de Janeiro: Elsevier, 2004.

BONAVIDES, Paulo. Curso de Direito Constitucional. 26 ed. atual. São Paulo: Malheiros, 2011.

BORGES, Maria Creusa de Araújo. Do direito à educação nos documentos internacionais de proteção dos direitos humanos - o caso da educação superior. Orientadora: Rosa Godoy. 2009. 98 f. Dissertação (Mestrado em Ciências Jurídicas) - Centro de Ciências Jurídicas, Universidade Federal da Paraíba, João Pessoa, 2009.

BORGES, Maria Creusa de Araújo. Princípios norteadores da educação em direitos humanos na instituição universitária. Verba Juris, João Pessoa, ano 7, n. 7, p. 133-175, jan./dez. 2008.

CAMPBELL, Alastair V. Uma visão internacional da bioética. In: GARRAFA, Volnei; COSTA, Sérgio Ibiapina F. (org.). A bioética no século XXI. Brasília: Editora Universidade de Brasília, 2000. p. 25-35.

CASADO, María. Presentatión de la obra. In: CASADO, María (coord.). Sobre la dignidad y los principios: análisis de la Declaración Universal sobre Bioética y Derechos Humanos de la Unesco. Barcelona: Ed. Civitas, 2009a. p. 19-23.

CASADO, María. Educación, formación e información en materia de bioética. In: CASADO, María (Coord.). Sobre la dignidad y los principios: análisis de la Declaración Universal sobre Bioética y Derechos Humanos de la Unesco. Barcelona: Ed. Civitas, 2009b. p. 509-521.

COMPARATO, Fábio Konder. A afirmação histórica dos direitos humanos. 4. ed. São Paulo: Saraiva, 2005.

DORA, Cristiana Lima; TEIXEIRA PRIMO, Fabian; ARAÚJO, Gabriela de Moraes Soares. Reflexões bioéticas acerca da inovação em nanomedicamentos. Revista Bioética y Derecho, Barcelona, v. 45, p. 197-212, 2019.

FLORES, Joaquín Herrera. A (re)invenção dos direitos humanos. Tradução Carlos Roberto Diogo Garcia, Antônio Henrique Graciano Suxberger e Jefferson Aparecido Dias. Florianópolis: Fundação Boiteux, 2009.

FREIRE, Songeli. Temas de bioética e de biossegurança para uso de professores da educação secundária na preparação da autonomia de jovens entre 12 e 17 anos. Revista Bioética y Derecho, Barcelona, v. 44, p. 103-120, 2018.

GARRAFA, Volnei; COSTA, Sérgio Ibiapina F. Prefácio. In: GARRAFA, Volnei; COSTA, Sérgio Ibiapina F. A bioética no século XXI. Brasília: Editora Universidade de Brasília, 2000. p. 9-10.

GONÇALVES, Leonardo A. Direitos sociais: cidadania, política e justiça. Rio de Janeiro: Sinergia, 2013.

HAVE, Henk ten. The future of bioethics education. In: PORTO, Dora et al. (org.). Bioética: saúde, pesquisa, educação. Brasília: CFM; SBB, 2014. p. 307-322. Vol. 2.

MAZZUOLI, Valerio de Oliveira. Curso de direitos humanos. 4 ed. rev., atual. e ampl. Rio de Janeiro: Forense; São Paulo: Método, 2017. 


\section{Direito登 Debate}

A EDUCAÇÃO EM BIOÉTICA NA DECLARAÇÃO UNIVERSAL SOBRE BIOÉTICA E DIREITOS HUMANOS

Cristiani Pereira de Morais Gonzalez - Maria Creusa de Araújo Borges

MORIN, Edgar. Os sete saberes necessários à educação do futuro. 2000. Disponível em: https://bioetica.catedraunesco.unb.br/ wp-content/uploads/2016/04/Edgar-Morin.-Sete-Saberes.pdf. Acesso em: 30 nov. 2018.

MOURA, Samantha Nagle Cunha de; MEDEIROS, Robson Antão de. Aborto na perspectiva da bioética e do biodireito: o caso do Projeto de Lei no 478/2007. In: MEDEIROS, Robson Antão de (org.). Biotecnologia, bioética e direitos humanos. João Pessoa: Editora da UFPB, 2015. p. 73-92.

NEVES, Maria do Céu Patrão. Bioética, biopolítica e a sociedade contemporânea. In: PORTO, Dora et al. (org.). Bioética: saúde, pesquisa, educação. Brasília: CFM; SBB, 2014. p. 143-167. Vol. 2.

OLIVEIRA, Fátima. Bioética: uma face da cidadania. São Paulo: Moderna, 1997.

OLIVEIRA, Aline Alburquerque S. de; VILLAPOUCA, Karin Calazans; BARROSO, Wilton. Perspectivas epistemológicas da bioética brasileira a partir da teoria de Thomas Kuhn. In: GARRAFA, Volnei; CORDÓN, Jorge (org.). Pesquisas em bioética no Brasil de hoje. São Paulo: Gaia, 2006. p. 19-44.

ONU. Organização das Nações Unidas. Declaración y Programa de Acción de Viena. 1993. Disponível em: https://www.ohchr. org/Documents/Events/OHCHR20/VDPA_booklet_Spanish.pdf. Acesso em: 19 fev. 2019.

ONU. Organização das Nações Unidas. Pacto Internacional de Derechos Económicos, Sociales y Culturales. 1966. Disponível em: https://www.ohchr.org/Documents/Professionallnterest/cescr_SP.pdf. Acesso em: 18 fev. 2019.

ONU. Organização das Nações Unidas. Declaración Universal de Derechos Humanos. 1948. Disponível em: https://www.ohchr. org/EN/UDHR/Documents/UDHR_Translations/spn.pdf. Acesso em: 17 fev. 2019.

PETERKE, Sven. Os direitos humanos coletivos e a proteção dos interesses fundamentais da humanidade: avanços e impasses. In: FEITOSA, Maria Luiza Alencar Mayer et al. (org.). Direitos humanos de solidariedade: avanços e impasses. Curitiba: Appris, 2013. p. 17-88.

RAMOS, André de Carvalho. Processo internacional de direitos humanos: análise dos sistemas de apuração de violações de direitos humanos e implementação das decisões no Brasil. Rio de Janeiro: Renovar, 2002.

REGO, Sérgio; ROSITO, Margaréte May Berkenbrock; YAMADA, Kiyomi Nakanishi. Didática, formação de professores e ensino de Bioética. In: ANJOS, Márcio Fabri dos; SIQUEIRA, José Eduardo de (org.). Bioética no Brasil: tendências e perspectivas. Aparecida: Ideias \& Letras; São Paulo: Sociedade Brasileira de Bioética, 2007. p. 129-141.

SARLET, Ingo Wolfgang. A eficácia dos direitos fundamentais: uma teoria geral dos direitos fundamentais na perspectiva constitucional. 12. ed. rev. atual e ampl. Porto Alegre: Livraria do Advogado Editora, 2015.

SILVA, Reinaldo Pereira e. Biodireito: a nova fronteira dos direitos humanos. São Paulo: LTr, 2003.

SILVA; Luís Gustavo Magnata; MEDEIROS, Robson Antão de. Biotecnologia e controle social: a amplitude da bióetica no debate da sociedade atual. In: MEDEIROS, Robson Antão de (org.). Biotecnologia, bioética e direitos humanos. João Pessoa: Editora da UFPB, 2015. p. 179-195.

UNESCO. Organização das Nações Unidas para a Educação, a Ciência e a Cultura. Declaración Universal sobre Bioética y Derechos Humanos. 2005. Disponível em: https://unesdoc.unesco.org/ark:/48223/pf0000146180_spa. Acesso em: 3 dez. 2018.

ZANCANARO, Lourenço. Bioética, direitos humanos e vulnerabilidade. In: BARCHIFONTAINE, Christian de Paul de; ZOBOLI, Elma (org.). Bioética, vulnerabilidade e saúde. Aparecida: Idéias \& Letras; São Paulo: Centro Universitário São Camilo, 2007. p. 46-60. 